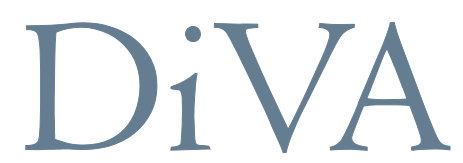

http://uu.diva-portal.org

This is the pre-peer reviewed version of the following article:

Abbott, J. K.; Bensch, S.; Gosden, T. P.; Svensson, E. I. "Patterns of differentiation in a colour polymorphism and in neutral markers reveal rapid genetic changes in natural damselfly populations" Molecular Ecology, 2008, Vol. 17, Issue 6, pp. 1597-1604 http://dx.doi.org/10.1111/j.1365-294X.2007.03641.x

The definitive version is available at http://www3.interscience.wiley.com. Access to the definitive version may require subscription. 


\section{Patterns of differentiation in a colour polymorphism and in neutral markers reveal rapid genetic changes in natural populations}

J. K. Abbott*, S. Bensch, T. P. Gosden, and E. I. Svensson

Department of Animal Ecology

Ecology Building

Lund University

SE-223 63 Lund, Sweden

*Author for correspondence: abbottj@queensu.ca

Current address:

Department of Biology

Queen's University

Kingston, Ont.

Canada K7L 3N6

Phone: 613-533-6000 x77464

Fax: 613-533-6617

Running title: Patterns of selection and polymorphism

Keywords: extinction-recolonization dynamics, frequency-dependence, genetic drift, nonequilibrium conditions, population divergence, AFLP 


\section{ABSTRACT}

2 The existence and mode of selection operating on heritable adaptive traits can be inferred by

3 comparing population differentiation in neutral genetic variation between populations (often

4 using $\mathrm{F}_{\mathrm{st}}-$-values) with the corresponding estimates for adaptive traits. Such comparisons

5 indicate if selection acts in a diversifying way between populations, in which case

6 differentiation in selected traits is expected to exceed differentiation in neutral markers

$7 \quad\left(\mathrm{~F}_{\mathrm{st}}(\right.$ selected $)>\mathrm{F}_{\mathrm{st}}($ neutral $\left.)\right)$, or if negative frequency-dependent selection maintains genetic

8 polymorphisms and pulls populations towards a common stable equilibrium $\left(\mathrm{F}_{\text {st }}(\right.$ selected $)<$

$9 \quad \mathrm{~F}_{\mathrm{st}}\left(\right.$ neutral)). Here we compared $\mathrm{F}_{\mathrm{st}}$-Values for putatively neutral data (obtained using AFLP)

10 with estimates of differentiation in morph frequencies in the colour-polymorphic damselfly

11 Ischnura elegans. We found that in the first year (2000), population differentiation in morph

12 frequencies was significantly greater than differentiation in neutral loci, while in 2002 (only

13 two years and two generations later), population differentiation in morph frequencies had

14 decreased to a level significantly lower than differentiation in neutral loci. Genetic drift as an

15 explanation for population differentiation in morph frequencies could thus be rejected in both

16 years. These results indicate that the type and/or strength of selection on morph frequencies

17 in this system can change substantially between years. We suggest that an approach to a

18 common equilibrium morph frequency across all populations, driven by negative frequency-

19 dependent selection, is the cause of these temporal changes. We conclude that inferences

20 about selection obtained by comparing $\mathrm{F}_{\mathrm{st}}$-values from neutral and adaptive genetic variation

21 are most useful when spatial and temporal data is available from several populations and time

22 points and when such information is combined with other ecological sources of data. 
INTRODUCTION

Comparing population differentiation of neutral loci and loci presumed to be subject to selection is a common way to indirectly infer the operation of selection in natural populations (McKay \& Latta 2002), for instance by comparing $\mathrm{F}_{\mathrm{st}}$-values for neutral loci with those for loci suspected to be subject so selection (Lynch \& Walsh 1998). If $F_{\text {st }}$ (selected) $>F_{s t}$ (neutral) then populations show greater differentiation than expected by genetic drift, which can be a result of adaptation to local environmental conditions (Lynch \& Walsh 1998). If $\mathrm{F}_{\mathrm{st}}($ selected) $<\mathrm{F}_{\mathrm{st}}($ neutral) then populations show less differentiation in adaptive traits than expected by drift, indicating that similar selection pressures are preserving trait values over an extended geographical area (Lynch \& Walsh 1998). This latter pattern may occur when negative frequency-dependent selection maintains a genetic polymorphism at a common stable equilibrium shared by a number of populations (Andrés, Sánchez-Guillén, \& Cordero Rivera 2000). Finally, when $F_{s t}($ selected $)=F_{s t}($ neutral $)$, population differentiation in the trait of interest does not exceed the expectation from genetic drift. Indirect studies of selection of this kind are particularly useful in the context of discrete heritable polymorphisms since some sort of balancing selection is usually considered necessary to maintain such polymorphisms over evolutionary time (Mazer \& Damuth 2001), and the genetic basis of the polymorphism is often known (Andrés, Sánchez-Guillén, \& Cordero Rivera 2000; Cameron 2001; Jorgensen, Richardson, \& Andersson 2006; Kärkkäinen, Løe, \& Ågren 2004; Schemske \& Bierzychudek 2001).

Here, we apply this analytical approach to the colour-polymorphic damselfly Ischnura elegans, in order to infer if this polymorphism is subject to selection. Males of I. elegans are monomorphic, but females may belong to one of three distinct phenotypic morphs: the male- 
like Androchrome morph, or one of the two more cryptic morphs, Infuscans and Infuscansobsoleta (Corbet 1999). Previous field studies have suggested that the morphs are subject to negative frequency-dependent selection caused by male mating harassment (Gosden \& Svensson 2007; Svensson, Abbott, \& Härdling 2005). The more common a morph is in the population, the more it is harassed by males, resulting in decreased female fecundity of common morphs (Svensson, Abbott, \& Härdling 2005). In addition, the morphs differ in morphology, development time, and fecundity (Abbott \& Svensson 2005; Abbott 2006; Svensson \& Abbott 2005; Svensson, Abbott, \& Härdling 2005), suggesting that the female morphs are phenotypically integrated alternative strategies. Given these morph-specific differences, it is possible that each morph exploits a slightly different ecological niche. If population differentiation in morph frequencies is found to be greater than expected from genetic drift, this pattern may reflect local adaptation to differing environmental conditions. On the other hand, if negative frequency-dependent selection operates on this polymorphism, the theoretical expectation at equilibrium would be that population differentiation in morph frequencies should be less than expected from genetic drift (Andrés, Sánchez-Guillén, \& Cordero Rivera 2000). Since populations of this species show continual and rapid change in morph frequencies (Svensson, Abbott, \& Härdling 2005) they may be approaching a common equilibrium determined by negative frequency-dependent selection, but on different population-specific trajectories. If this is the case, then population differentiation may be greater than expected from drift despite the fact that the equilibrium value is similar in all populations.

Although both diversifying and homogenizing selection have been inferred in other polymorphic damselfly species in the past (Andrés, Sánchez-Guillén, \& Cordero Rivera 2000; Wong, Smith, \& Forbes 2003), these previous studies have either relied on single point 
estimates in time and/or else used relatively few focal populations (between 2 and 5). Our study differs from these previous studies in that we have both compared more populations (12) and replicated our study across two years (2000 and 2002), a period of three generations. Interestingly, we found that despite being only two years apart, our inferences about selection at each point changed substantially over this time period. We suggest that this is because our study populations have not yet reached their evolutionary equilibria. Non-equilibrium dynamics of this kind may, however, be a general feature of natural populations of both this and other species. Our results will therefore have general implications for the utility of indirect inferences of selection, which is currently a popular research approach among evolutionary biologists and molecular ecologists (see references above).

\section{MATERIALS AND METHODS}

\section{Field work and study organism}

Our study took place in a series of populations of Ischnura elegans in southern Sweden (Fig. 1), which is at the northern end of its distributional range in Europe (Askew 1988). This damselfly species is univoltine in Sweden, with one non-overlapping generation per year (Corbet 1999). As discussed above, I. elegans has three female morphs, one of which (the Androchrome morph) is a male mimic (Askew 1988; Svensson, Abbott, \& Härdling 2005). Morph identity in Ischnura elegans is controlled by a single locus with 3 alleles in a dominance hierarchy, and with expression sex-limited to females (Sánchez-Guillén, Van Gossum, \& Cordero Rivera 2005). The dominance-hierarchy of the morph alleles is linear, with the Androchrome allele (denoted by "A") dominant over the two other alleles (denoted by "I" for Infucscans and "IO” for Infuscans-obsoleta), i. e. A > I > IO (Sánchez-Guillén, 
101 phenotype, if it were found, could therefore still contain alleles of the two other morphs, which would be carried by heterozygotes.

Male and female Ischnura elegans were captured and collected from 12 study populations outside Lund, in southern Sweden (Flyinge 30A1, Flyinge 30A3, Genarp, Gunnesbo, Habo,

106 Höje å 6, Höje 7, Höje å 14, Lomma, Vallby, and Vombs vattenverk; Fig. 1). Of these populations, several are located in recently artificially created wetlands (Flyinge 30A1, Flyinge 30A3, Höje å 6, Höje 7, and Höje å 14) while others are either naturally-occurring or else artificially created but long-established ponds (age >20 years at the time of sampling;

110 Genarp, Gunnesbo, Habo, Lomma, Vallby, and Vombs vattenverk). Field work took place

111 from the end of May until the beginning of August using hand-held nets in the summers of 2000 and 2002. All females were classified with respect to morph. For more details on field data procedures, see Svensson \& Abbott (2005) and Abbott (2006). Individuals used in

114 genetic analyses were stored in ethanol in small plastic tubes. We sampled between 8 and 34 115 individuals for genetic analysis (mean \pm SD: 20.61 \pm 7.30 ), and between 12 and 109 individuals

116 for calculation of morph frequency differentiation (mean \pm SD: 53.44 \pm 28.45$)$ from each

117 population in each year. Although southern European populations of I. elegans may

118 systematically vary in morph frequencies over the summer (Cordero 1992), this is unlikely to

119 be a problem here. Previous analysis on these and other study populations shows that though 120 the female morphs differ significantly in emergence time, the difference is only about 3 days 121 (Abbott \& Svensson 2005). These study populations were sampled repeatedly over typically much longer periods (mean \pm SD: $31.17 \pm 18.31$ days). 
126 Amplified Fragment Length Polymorphism (AFLP) was carried out as described in Vos et al.

127 (1995). Ten different primer combinations were tested, and three selected for final analysis:

$128 \mathrm{E}_{\mathrm{TCG}}$ and $\mathrm{M}_{\mathrm{CGG}}, \mathrm{E}_{\mathrm{TAG}}$ and $\mathrm{M}_{\mathrm{CGC}}, \mathrm{E}_{\mathrm{TAG}}$ and $\mathrm{M}_{\mathrm{CGAC}}$. Samples were run using gel

129 electrophoresis and 46 polymorphic sites were scored for presence/absence of bands by JA

130 and checked blindly by TG. Many more polymorphic sites were evident on the

131 polyacrylamide gels, but only 46 were deemed suitable for analysis. This is because $I$.

132 elegans appears to have a relatively large genome (Staffan Bensch, personal observation),

133 resulting in the production of many bands located too close together for accurate scoring.

134 Data was analyzed using Arlequin (Schneider, Roessli, \& Excoffier 2000). To obtain an error

135 rate due to the amplification and electrophoresis steps (Bonin et al. 2004), 14 individuals were

136 amplified and scored twice. The error rate for these steps was determined to be ca. $4.1 \%$,

137 which is comparable to that found in other studies (Bonin et al. 2004 and references therein).

138 Unfortunately, we were unable to determine an error rate for the extraction step since entire

139 individuals were used during extraction, making it impossible to later repeat this step on the

140 same individual. Samples were not analyzed in year- or population-batches to avoid

141 confounding effects due to lab artefact.

142

143 For morph frequency differentiation, we calculated morph allele frequency estimates for each

144 population and year from phenotypic morph frequencies using the Hardy-Weinberg formula

145 (Hartl \& Clark 1997), and then calculated $\mathrm{F}_{\mathrm{st}}$-values based on the estimated allele frequencies.

146 This approach was also used by Andrés, Sánchez-Guillén, \& Cordero Rivera (2000) in a

147 similar study. 
149 Due to small and highly fluctuating population sizes, three populations could not be sampled

150 in both years. Because of this, we first analysed the results from each year separately, and

151 then carried out a two-way ANOVA with Type of data (AFLP or Morph) and Year (2000 or

152 2002) as factors on a reduced data set with 9 populations that had been sampled in both years.

153 For this analysis, a significant effect of Type would indicate that populations had higher

154 overall differentiation in one or the other type of data (for example, consistently higher

155 differentiation in morph frequencies than at neutral loci). A significant effect of year would

156 indicate that populations had higher overall differentiation in one year (for example if

157 differentiation decreased over time). A significant interaction effect would indicate that the

158 effect of type of data was dependent on year. We also checked the robustness of our results to

159 low sample sizes, by testing for differences between neutral and morph frequency data using a

160 subset of the data where populations with small sample sizes for either measure $(\leq 15$

161 individuals) were excluded. This reduced data-set included a total of 6 populations (Flyinge

162 30A3, Genarp, Habo, Höje å 6, Lomma, and Vomb). To see if changes in differentiation

163 between years were due to moderate changes in all populations, or large changes in just a few

164 populations, we also calculated $\mathrm{F}_{\mathrm{st}}$-values for differentiation between years within

165 populations. Since $\mathrm{F}_{\mathrm{st}}$-values are calculated in a pairwise way they are not independent, so

166 significance testing and calculation of means was carried out using resampling procedures

167 (permuation tests and bootstrapping) in the program Resampling Stats (Simon 2000).

169 Although changes in morph frequencies in these populations have been previously analysed

170 as part of a larger data set (Svensson \& Abbott 2005), we also carried out a separate analysis

171 of morph frequency changes in these particular populations and years, in order to try to

172 directly relate changes in $\mathrm{F}_{\mathrm{st}}$-values to changes in morph frequencies. Because the

173 frequencies of the three morphs are not independent, we decided to analyse changes in 
174 Androchrome frequency only. This is because Androchromes are the most common morph,

175 and therefore provide the most reliable morph frequency estimates, and also because previous

176 analysis indicated that Androchromes had decreased in frequency over the study period

177 (Svensson \& Abbott 2005). We therefore tested for changes in mean Androchrome frequency

178 and in the variance in Androchrome frequencies between years using a weighted one-way

179 ANOVA, with weighting according to the number of individuals captured in the population,

180 and degrees of freedom equal to one less than the number of populations in the analysis.

181

182

183

184 For the full data set, population differentiation in morph-frequencies was significantly greater

194 To investigate if these changing patterns of differentiation arose from qualitatively different

195 temporal dynamics of the two kinds of markers (i. e. morph-data and AFLP-data), we performed a two-way ANOVA with Type of data (morph or AFLP), year (2000 and 2002) and their interaction as independent variables. There were no significant main effects of Type than population differentiation for the AFLP-markers in the year $2000(P=0.004)$, but not significantly different from population differentiation for the same AFLP-markers in 2002 $(P=0.166)$. However, if populations with small sample sizes $(\leq 15)$ are excluded, population differentiation in morph frequencies was significant for both years $(2000: P=0.003 ; 2002$ : $P<0.001)$ which strongly suggests that the lack of a significant effect in 2002 may be due to estimation errors from small population sample sizes. Thus, population differentiation in morph frequencies differed significantly from the neutral expectation in both seasons, although the direction of the difference reversed between years (Fig. 2). of data or Year on population differentiation (both $P>0.1$ ), but there was a significant 
interaction effect (Type* Year: $\left.\mathrm{F}_{1,144}=13.41, P<0.001\right)$. Thus, population differentiation

200 changed significantly between years, but in qualitatively different ways for the two types of 201 markers (Fig. 2). Population differentiation in morph frequencies decreased from 2000 to 2002 ( $P=0.028$, Fig. 2), while differentiation at neutral loci (AFLP) increased over the same time period $(P<0.001$, Fig. 2$)$. $\mathrm{F}_{\mathrm{st}}$-values used in these analyses are shown in Table 1. More 204 evidence of qualitatively different dynamics for neutral genetic data and morph frequency 205 data comes from analysis of the amount of differentiation between years within populations. 206 For neutral data, there are approximately equal amounts of differentiation between years in each population (Table 2), and there is very little difference in mean differentiation between new and old populations (new: 0.039, old: 0.044). In contrast, morph frequency differentiation between years is very large in some populations (e.g. Flyinge 30A1, Höje å 6),

210 and very small in others (e.g. Genarp, Habo), and mean differentiation is much higher in new 211 populations than in old (new: 0.148, old: 0.020; Table 2).

Mean Androchrome frequency across all populations decreased significantly between 2000

214 and $2002(P=0.030$, Fig. 3$)$ as did the between-population variance in Androchrome

215 frequencies (Levene's test: $P<0.0001$, Fig. 3). This suggests that the temporal change in 216 morph frequency differentiation was largely a result of changes in frequency of the most 217 common female morph, the Androchromes.

\section{DISCUSSION}

221 Although comparing differentiation at neutral loci with differentiation in traits presumed to be under selection has been used extensively by plant biologists (Jorgensen, Richardson, \&

223 Andersson 2006; Kärkkäinen, Løe, \& Ågren 2004), relatively few studies of animals have 
been carried out to date (e.g. Andrés, Sánchez-Guillén, \& Cordero Rivera 2000). Similar studies on other polymorphic damselfly species (Andrés, Sánchez-Guillén, \& Cordero Rivera 2000; Wong, Smith, \& Forbes 2003) have revealed conflicting results. In one case differentiation in morph frequencies was found to be greater than expected from drift (Wong, Smith, \& Forbes 2003), and in another study on a sibling species of I. elegans (I. graellsii), morph frequency differentiation was found to be smaller than expected from drift (Andrés,

230 Sánchez-Guillén, \& Cordero Rivera 2000). The latter result is actually what is expected if negative frequency-dependent selection on this female polymorphism maintains all morphs in all populations (Andrés, Sánchez-Guillén, \& Cordero Rivera 2000). Finally, some other recent studies on polymorphic invertebrates (the scarlet tiger moth Callimorpha dominula, and the candy-stripe spider Enoplognatha ovata) have found that both drift and selection influence morph frequency fluctuations between generations (O'Hara 2005; Oxford 2005).

Interestingly, indirect inferences about selection based on our results varied between years. Population differentiation in morph frequencies was initially (in 2000) significantly higher than at neutral loci (Fig. 2), which is consistent with divergent selection and local adaptation 240 as a cause of population differentiation in this polymorphism. However, only two generations 241 later (in 2002), differentiation in morph frequencies was significantly lower than

242 differentiation at neutral loci, which may result if morph frequencies are rapidly converging to 243 a common equilibrium. This pattern could also be produced if selection pressures due to 244 abiotic factors vary stochastically, with the scale of selection varying from local to regional 245 between years, and with no or weak net selection in some years. However, we believe that an ongoing approach to equilibrium is the more likely scenario, for reasons outlined below. If

247 negative frequency-dependence causes morph frequencies to converge on the same 248 equilibrium frequency and each population approaches along a different trajectory, this will 
result in high differentiation in morph frequencies at the start of this process and low

250 differentiation at the end. Our results would therefore demonstrate movement towards a 251 stable equilibrium morph frequency across our study populations.

In order to confirm that our study populations have undergone this process, we would ideally need data from additional years to determine whether populations have in fact now reached a stable equilibrium or if patterns of differentiation fluctuate wildly between years. Although data on morph frequencies are available from 2000 onwards, individuals were only sampled for genetic analysis in 2000 and 2002 because large changes in the neutral population differentiation (Fig. 2) were not expected when we started this study. A significant increase in neutral differentiation over this short time period is surprising, and shows (Fig. 2) that these populations are unlikely to be in equilibrium for either their neutral markers or their morph frequencies. For example, we have observed that in our study area in southern Sweden, newly established populations of I. elegans are subject to frequent extinctions and recolonizations (E. I. Svensson, unpublished data), which is expected to affect patterns of 264 neutral genetic differentiation between populations (Ingvarsson, Olsson, \& Ericson 1997). 265 Sexual selection in this species also appears to be strong, since males engage in "scramble" competition (Andersson 1994; Corbet 1999), and there is evidence of temporal variation in

267 the strength and direction of sexual selection on male body size (Gosden \& Svensson, 268 submitted). Both these processes (i. e. extincition-recolonization dynamics and sexual 269 selection) should result in consistently small effective population sizes, which will act to 270 increase the importance of genetic drift to neutral population differentiation (Lynch \& Walsh 271 1998). Measures of neutral differentiation between years in each population also suggest

272 small effective population sizes, since there are consistently large amounts of neutral

273 differentiation between years within populations (Table 2). 
275 Several of our study populations are located in recently artificially created wetlands

276 (Svensson \& Abbott 2005), and such newly colonized ponds may, due to random colonization 277 by I. elegans, start off with very different morph frequencies, i. e. founder effects. Moreover, 278 genotype-specific dispersal (Garant et al. 2005) or differential colonization ability of the 279 morphs according to site could also lead to overrepresentation of certain morphs in new 280 populations, although there is little direct evidence of morph-specific dispersal (Conrad et al. 281 2002). There is, however, indirect evidence of morph-specific dispersal from patterns of 282 Androchrome frequency changes in new and old populations (Svensson \& Abbott 2005). 283 Newly colonized populations have higher Androchrome frequencies during early 284 establishment phases, while these frequencies decline and approach the levels of old 285 populations over time (Svensson \& Abbott 2005). In addition, measures of differentiation in morph frequencies between years in each population show that new populations have higher mean differentiation between years than old populations (Table 2), consistent with the result that morph frequencies are changing more rapidly between years in new populations.

Colonization of newly-established ponds in combination with morph-specific dispersal and/or

290 frequent recolonizations could potentially explain why population differentiation in morph 291 frequencies was initially greater than expected from drift. After colonization, negative 292 frequency-dependent selection could then act on these populations to bring them closer to a 293 common equilibrium frequency.

295 Despite the paucity of neutral genetic data, field data on morph frequency changes in these 296 and other populations over several years (Svensson \& Abbott 2005) can provide some 297 supporting evidence for the approach to a common equilibrium hypothesis. Analysis of 298 morph frequencies in the 12 populations which are the focus of this study confirmed that both 
the frequency of Androchromes and the variance in Androchrome frequency decreased over

300 time (Fig. 3). The observed decrease in the variance in Androchrome frequencies is clearly

301 consistent with a decrease in overall differentiation in morph frequencies (Fig. 2). In a longer

302 longitudinal study, Svensson and Abbott (2005) found that Androchrome frequencies

303 decreased in most populations over a four-year period. Androchrome frequencies in these

304 study populations during this period were typically between $60 \%$ and $90 \%$, which is higher

305 than frequencies reported elsewhere in Europe (Italy: 55\% Androchromes, Cordero Rivera \&

306 Andrés 2001; Ukraine: 24\% Androchromes, Gorb 1999).

308 Thus, morph frequencies in our study populations may be in the process of approaching an

309 equilibrium that is closer to the lower frequency of Androchromes in more southerly

310 populations. At this point, we can not rule out the possibility that equilibrium frequencies

311 also differ geographically. However, an approach to a low-Androchrome equilibrium

312 frequency is also supported by a population genetic model based on fecundity data to estimate

313 frequency-dependent selection (Svensson, Abbott, \& Härdling 2005). Results from

314 population genetic modelling and simulations indicate that the equilibrium frequency of

315 Androchromes may be substantially lower than the frequencies that we observed at the onset

316 of our study in 2000 (Svensson, Abbott, \& Härdling 2005). These independent lines of

317 evidence all suggest that an ongoing approach to a common equilibrium frequency.

319 An important assumption to inferences about the existence of selection from comparisons

320 with molecular data, is that the study populations have reached their evolutionary equilibria.

321 As we have discussed above, this is unlikely to be true in our case. However, indirect

322 inferences about the action of selection, such as this study, are still valuable, particularly

323 when combined with additional ecological information, e. g. measurements of fitness 
324 differences between morphs or genotypes, information about dispersal and gene flow, and

325 longitudinal population studies (Abbott \& Svensson 2005; Svensson \& Abbott 2005;

326 Svensson, Abbott, \& Härdling 2005). Our results thus demonstrate the importance of

327 sampling as many populations and time points as possible when studying non-equilibrium

328 systems, and should hopefully stimulate future research in this area.

\section{ACKNOWLEDGEMENTS}

332 Thanks to Stefan Andersson, Roger Härdling, Fabrice Eroukhmanoff, Kristina Karlsson, and

333 Anna Runemark and several anonymous referees for comments on this manuscript. Thanks

334 also to Stefan Gödderz for help in the DNA-lab, and to Anna Antonsson, Audrey Coreau,

335 Hedvig Hogfors, Jane Jönsson, Anna Persson, and Patrik Stenroth for field assistance.

336 Financial support has been provided by the Swedish Research Council ("Vetenskapsrådet";

337 VR), Oscar \& Lilli Lamms Stiftelse and The Swedish Council for Environment, Agriculture

338 and Spatial Planning (FORMAS, to E. I. S.) 
343 Abbott J \& Svensson EI (2005) Phenotypic and genetic variation in emergence and

344 development time of a trimorphic damselfly. Journal of Evolutionary Biology, 18, pp. 1464$345 \quad 1470$.

346 Abbott JK (2006) Ontogeny and population biology of a sex-limited colour polymorphism, 347 Doctoral, Lund University, Lund, Sweden.

348 Andersson M (1994) Sexual selection. Princeton University Press, Princeton.

349 Andrés JA, Sánchez-Guillén RA, \& Cordero Rivera A (2000) Molecular evidence for 350 selection on female colour polymorphism in the damselfly Ischnura graellsii. Evolution, 54, 351 pp. 2156-2161.

352 Askew RR (1988) The dragonflies of Europe. Harley Books, Colchester, Essex.

353 Bonin A, Bellemain E, Bronken Eidesen P, Pompanon F, Brochmann C, \& Taberlet P (2004)

354 How to track and assess genotyping errors in populations genetics studies. Molecular 355 Ecology, 13, pp. 3261-3273.

356 Cameron RAD (2001) Cepaea nemoralis in a hostile environment: continuity, colonizations 357 and morph-frequencies over time. Biological Journal of the Linnean Society, 74, pp. 255-264.

358 Conrad KF, Willson KH, Whitfield K, Harvey IF, Thomas CJ, \& Sherratt TN (2002)

359 Characteristics of dispersing Ischnura elegans and Coenagrion puella (Odonata): age, sex, 360 size, morph and ectoparasitism. Ecography, 25, pp. 439-445. 
361 Corbet PS (1999) Dragonflies: behaviour and ecology of Odonata. Harley Books, Colchester, 362 Essex.

363 Cordero Rivera A \& Andrés JA (2001) Estimating female morph frequencies and male mate 364 preferences of polychromatic damselflies: a cautionary note. Animal Behaviour, 61, p. F1-F6.

365 Cordero A (1992) Density-dependent mating success and colour polymorphism in females of 366 the damselfly Ischnura graellsii (Odonata: Coenagrionidae). Journal of Animal Ecology, 61, 367 pp. $769-780$.

368 Garant D, Kruuk LEB, Wilkin TA, McCleery RH, \& Sheldon BC (2005) Evolution driven by 369 differential dispersal within a wild bird population. Nature, 433, pp. 60-65.

370 Gorb SN (1999) Visual cues in mate recognition in the damselfly Ischnura elegans

371 (Zygoptera: Coenagrionidea). International Journal of Odonatology, 2, pp. 83-93.

372 Gosden TP \& Svensson EI (2007) Female sexual polymorphism and fecundity consequences

373 of male mating harassment in the wild. PLoS One, 2, p. e580.

374 Hartl DL \& Clark AG (1997) Principles of population genetics, 3rd edition. Sinauer 375 Associates, Sunderland, MA.

376 Ingvarsson PK, Olsson K, \& Ericson L (1997) Extinction-recolonization dynamics in the 377 mycophagous beetle Phalacrus substriatus. Evolution, 51, pp. 187-195.

378 Jorgensen TH, Richardson DS, \& Andersson S (2006) Comparative analyses of population 379 structure in two subspecies of Nigella degenii: evidence for diversifying selection on pollen380 color polymorphism. Evolution, 60, pp. 518-528. 
381 Kärkkäinen K, Løe G, \& Ågren J (2004) Population structure in Arabidopsis lyrata: evidence

382 for divergent selection on trichome production. Evolution, 58, pp. 2831-2836.

383 Lynch M \& Walsh B (1998) Genetics and analysis of quantitative traits. Sinauer Associates, 384 Inc., Sunderland, MA.

385 Mazer SJ \& Damuth J (2001) Nature and causes of variation, In: Evolutionary ecology, 386 concepts and case studies, (ed. Fox CW, Roff DA, \& Fairbairn DJ, eds.), pp. 3-15. Oxford 387 University Press, New York, USA.

388 McKay JK \& Latta RG (2002) Adaptive population divergence: markers, QTL and traits. 389 Trends in Ecology and Evolution, 17, pp. 285-291.

390 O'Hara RB (2005) Comparing the effects of genetic drift and fluctuating selection on 391 genotype frequency changes in the scarlet tiger moth. Proceedings of the Royal Society of 392 London B, 272, pp. 211-217.

393 Oxford GS (2005) Genetic drift within a protected polymorphism: enigmatic variation in 394 color-morph frequencies in the candy-stripe spider, Enoplognatha ovata. Evolution, 59, pp. $395 \quad 2170-2184$.

396 Sánchez-Guillén RA, Van Gossum H, \& Cordero Rivera A (2005) Hybridization and the 397 inheritance of female colour polymorphism in two Ischnurid damselflies (Odonata: 398 Coenagrionidae). Biological Journal of the Linnean Society, 85, pp. 471-481.

399 Schemske DW \& Bierzychudek P (2001) Evolution of flower colour in the desert annual 400 Linanthus parryae: Wright revisited. Evolution, 55, pp. 1269-1282.

401 Schneider S, Roessli D, \& Excoffier L. (2000) Arlequin. 
402 Simon JL. (2000) Resampling stats. Arlington, VA, Resampling Stats Inc.

403 Svensson EI \& Abbott J (2005) Evolutionary dynamics and population biology of a

404 polymorphic insect. Journal of Evolutionary Biology, 18, pp. 1503-1514.

405 Svensson EI, Abbott J, \& Härdling R (2005) Female polymorphism, frequency-dependence

406 and rapid evolutionary dynamics in natural populations. The American Naturalist, 165, pp.

$407 \quad 567-576$.

408 Vos P, Hogers R, Bleeker M, Reijans M, van de Lee T, Hornes M, Frijters A, Pot J, Peleman

409 J, Kuiper M, \& Zabeau M (1995) AFLP: a new technique for DNA fingerprinting. Nucleic

410 Acids Research, 23, pp. 4407-4414.

411 Wong A, Smith ML, \& Forbes MR (2003) Differentiation between subpopulations of a

412 polychromatic damselfly with respect to morph frequencies, but not neutral genetic markers.

413 Molecular Ecology, 12, pp. 3505-3513.

414

415 
Table 1: $\mathrm{F}_{\mathrm{st}}$-values for morph frequencies and neutral loci in the years 2000 and 2002. Some populations were not sampled in both years, and absent values are marked by a “_“. Neutral $\mathrm{F}_{\mathrm{st}}$-values were obtained from the analysis of 46 AFLP loci, while morph frequency $\mathrm{F}_{\mathrm{st}}$-values were obtained from allele frequency estimates calculated from phenotypic counts. A: Neutral differentiation in 2000. B: Neutral differentiation in 2002. C: Morph frequency differentiation in 2000. D: Morph frequency differentiation in 2002. Abbreviations are as follows: F1 = Flyinge 30A1, F3 = Flyinge 30A3, Ge = Genarp, Gu = Gunnesbo, Ha = Habo, Hof = Hofterups, H6 = Höje å 6, H7 = Höje å 7, H14 = Höje å 14, L= Lomma, $\mathrm{Va}=$ Vallby, and $\mathrm{Vo}=$ Vomb. Note that negative numbers simply denote an absence of differentiation, and not negative differentiation. Values that are significantly different from zero are in bold.

A)
F1
F3
$\mathrm{Ge}$
$\mathrm{Gu}$
$\mathrm{Ha}$
Hof
H6
H7
H14
L
$\mathrm{Va}$

F3

\subsection{5}

Ge

$\mathrm{Gu}$

Ha

Hof

H6

\subsection{1}

0.018

0.018

0.017

0.017

0.001
0.010

0.031

0.027

$-0.004$

0.022

$-0.0002$

0.011

0.012

0.045

\subsection{2}

0.004

$\begin{array}{lll}0.020 & 0.001 \quad 0.008\end{array}$




\begin{tabular}{|c|c|c|c|c|c|c|c|c|c|c|c|}
\hline H7 & - & - & - & - & - & - & - & & & & \\
\hline H14 & 0.039 & 0.017 & 0.018 & 0.028 & 0.010 & 0.019 & 0.006 & - & & & \\
\hline $\mathrm{L}$ & 0.012 & 0.004 & 0.009 & 0.016 & -0.017 & 0.017 & 0.004 & - & 0.022 & & \\
\hline $\mathrm{Va}$ & - & - & - & - & - & - & - & - & - & - & \\
\hline Vo & 0.001 & 0.009 & 0.016 & 0.045 & 0.006 & 0.011 & 0.016 & - & 0.041 & 0.005 & - \\
\hline \multicolumn{12}{|l|}{ B) } \\
\hline & $\mathrm{F} 1$ & F3 & $\mathrm{Ge}$ & $\mathrm{Gu}$ & $\mathrm{Ha}$ & Hof & H6 & $\mathrm{H} 7$ & H14 & $\mathrm{L}$ & $\mathrm{Va}$ \\
\hline $\mathrm{F} 3$ & 0.068 & & & & & & & & & & \\
\hline $\mathrm{Ge}$ & 0.105 & 0.028 & & & & & & & & & \\
\hline $\mathrm{Gu}$ & 0.025 & 0.018 & 0.047 & & & & & & & & \\
\hline $\mathrm{Ha}$ & 0.093 & 0.029 & 0.022 & 0.027 & & & & & & & \\
\hline Hof & - & - & - & - & - & & & & & & \\
\hline H6 & 0.094 & 0.021 & 0.017 & 0.031 & 0.021 & - & & & & & \\
\hline $\mathrm{H} 7$ & 0.101 & 0.023 & 0.007 & 0.043 & 0.014 & - & -0.001 & & & & \\
\hline H14 & 0.054 & 0.017 & 0.024 & 0.033 & 0.043 & - & 0.021 & 0.018 & & & \\
\hline
\end{tabular}




\begin{tabular}{|c|c|c|c|c|c|c|c|c|c|c|c|}
\hline $\mathrm{L}$ & $\mathbf{0 . 0 5 7}$ & 0.024 & 0.012 & 0.037 & -0.002 & - & 0.011 & -0.003 & 0.018 & & \\
\hline $\mathrm{Va}$ & 0.112 & 0.021 & 0.053 & 0.065 & 0.059 & - & 0.028 & 0.041 & 0.049 & 0.037 & \\
\hline Vo & 0.114 & 0.023 & 0.028 & 0.060 & 0.015 & - & 0.025 & 0.015 & $\mathbf{0 . 0 3 7}$ & 0.012 & 0.031 \\
\hline \multicolumn{12}{|l|}{ C) } \\
\hline & $\mathrm{F} 1$ & $\mathrm{~F} 3$ & $\mathrm{Ge}$ & $\mathrm{Gu}$ & $\mathrm{Ha}$ & Hof & H6 & $\mathrm{H} 7$ & H14 & $\mathrm{L}$ & $\mathrm{Va}$ \\
\hline F3 & -0.027 & & & & & & & & & & \\
\hline $\mathrm{Ge}$ & 0.102 & 0.059 & & & & & & & & & \\
\hline $\mathrm{Gu}$ & 0.064 & 0.031 & -0.017 & & & & & & & & \\
\hline $\mathrm{Ha}$ & 0.053 & 0.018 & -0.026 & -0.051 & & & & & & & \\
\hline Hof & 0.236 & 0.180 & 0.046 & 0.008 & 0.011 & & & & & & \\
\hline H6 & 0.092 & 0.104 & 0.115 & 0.056 & 0.057 & 0.066 & & & & & \\
\hline H7 & - & - & - & - & - & - & - & & & & \\
\hline H14 & 0.011 & 0.005 & 0.021 & -0.018 & -0.027 & 0.064 & 0.035 & - & & & \\
\hline $\mathrm{L}$ & -0.053 & 0.023 & 0.160 & 0.131 & 0.124 & 0.303 & 0.113 & - & 0.059 & & \\
\hline $\mathrm{Va}$ & - & - & - & - & - & - & - & - & - & - & \\
\hline
\end{tabular}




\begin{tabular}{|c|c|c|c|c|c|c|c|c|c|c|c|}
\hline Vo & 0.174 & 0.129 & 0.013 & -0.001 & -0.004 & -0.013 & 0.109 & - & 0.054 & 0.223 & - \\
\hline \multicolumn{12}{|l|}{ D) } \\
\hline & $\mathrm{F} 1$ & F3 & $\mathrm{Ge}$ & $\mathrm{Gu}$ & $\mathrm{Ha}$ & Hof & H6 & H7 & H14 & $\mathrm{L}$ & $\mathrm{Va}$ \\
\hline F3 & 0.112 & & & & & & & & & & \\
\hline $\mathrm{Ge}$ & 0.097 & -0.002 & & & & & & & & & \\
\hline $\mathrm{Gu}$ & 0.053 & 0.008 & -0.014 & & & & & & & & \\
\hline $\mathrm{Ha}$ & 0.105 & 0.015 & -0.014 & -0.011 & & & & & & & \\
\hline Hof & - & - & - & - & - & & & & & & \\
\hline H6 & 0.139 & -0.012 & 0.015 & 0.028 & 0.039 & - & & & & & \\
\hline H7 & 0.030 & -0.002 & -0.004 & -0.015 & 0.010 & - & 0.007 & & & & \\
\hline H14 & 0.073 & -0.013 & -0.010 & -0.010 & 0.004 & - & -0.007 & -0.020 & & & \\
\hline $\mathrm{L}$ & 0.065 & 0.003 & -0.012 & -0.016 & -0.006 & - & 0.019 & -0.013 & -0.011 & & \\
\hline $\mathrm{Va}$ & 0.027 & 0.118 & 0.064 & 0.030 & 0.051 & - & 0.163 & 0.056 & 0.083 & 0.049 & \\
\hline Vo & 0.118 & -0.011 & 0.001 & 0.011 & 0.018 & - & -0.013 & 0.001 & -0.011 & 0.006 & 0.123 \\
\hline
\end{tabular}


Table 2: $\mathrm{F}_{\mathrm{st}}$-values between years within each population for morph frequencies and neutral loci, in relation to population age. Populations with data missing in one year are excluded. For neutral loci, differentiation between years is similar across populations, and does not appear to be related to population age (mean new: 0.039, mean old: 0.044). For morph frequencies, differentiation between years varies across populations, and mean differentiation is much higher in new populations than in old (new: 0.148, old: 0.020). For details about classification of populations as new and old, see Materials and Methods. Note that negative numbers simply denote an absence of differentiation, and not negative differentiation. Values that are significantly different from zero are in bold.

Population Neutral data $\quad$ Morph frequencies Population age

$\begin{array}{llll}\text { Flyinge 30A1 } & \mathbf{0 . 1 0 4} & \mathbf{0 . 2 8 9} & \text { New } \\ \text { Flyinge 30A3 } & 0.015 & \mathbf{0 . 0 6 5} & \text { New } \\ \text { Genarp } & \mathbf{0 . 0 1 8} & -0.010 & \text { Old } \\ \text { Gunnesbo } & \mathbf{0 . 0 5 6} & -0.032 & \text { Old } \\ \text { Habo } & \mathbf{0 . 0 7 0} & -0.032 & \text { Old } \\ \text { Höje å 6 } & -0.010 & \mathbf{0 . 2 1 4} & \text { New } \\ \text { Höje å 14 } & \mathbf{0 . 0 4 8} & 0.025 & \text { New } \\ \text { Lomma } & \mathbf{0 . 0 3 6} & \mathbf{0 . 1 3 5} & \text { Old } \\ \text { Vomb } & \mathbf{0 . 0 3 8} & \mathbf{0 . 0 3 7} & \text { Old }\end{array}$




\section{FIGURE LEGENDS}

FIG. 1: Map of the study area showing locations of study sites (left), and their position in relation to the rest of Sweden (right). Abbreviations are as follows: F1 = Flyinge 30A1, F3 = Flyinge 30A3, Ge = Genarp, Gu = Gunnesbo, Ha = Habo, Hof = Hofterups, H6 = Höje å 6 , H7 = Höje å 7, H14 = Höje å 14, L = Lomma, Va = Vallby, and Vo = Vomb.

FIG 2: Mean $\mathrm{F}_{\mathrm{st}}$-values (with SEs) for morph frequencies and neutral data for years 2000 and 2002 for all 12 populations. Data for morph frequencies is based on analysis of allele frequencies estimated using the Hardy-Weinberg formula. Neutral data is based on analysis of 46 putatively neutral AFLP loci. If populations with small sample sizes are excluded, the differences between the types of data become even larger, and differentiation in morph frequencies is significantly higher than expected from drift in the year $2000(P=0.003)$, but significantly lower than expected from drift in $2002(P<0.0001)$.

FIG 3: Weighted mean Androchrome frequencies with standard errors for 2000 and 2002.

There is a significant decrease over time in both the mean Androchrome frequency $(P=0.030)$, and in the variance in Androchrome frequencies (Levene's test: $P<0.0001$ ). 


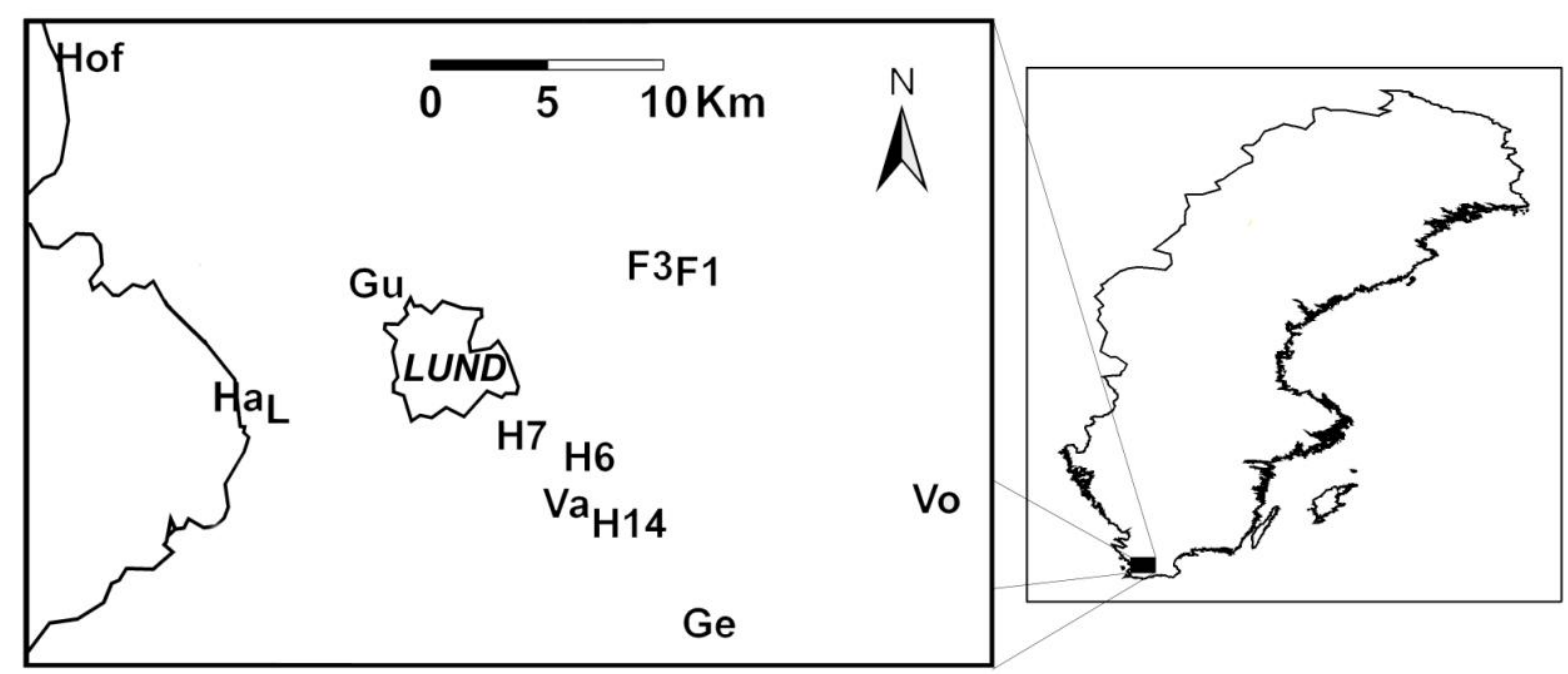

Figure 1 


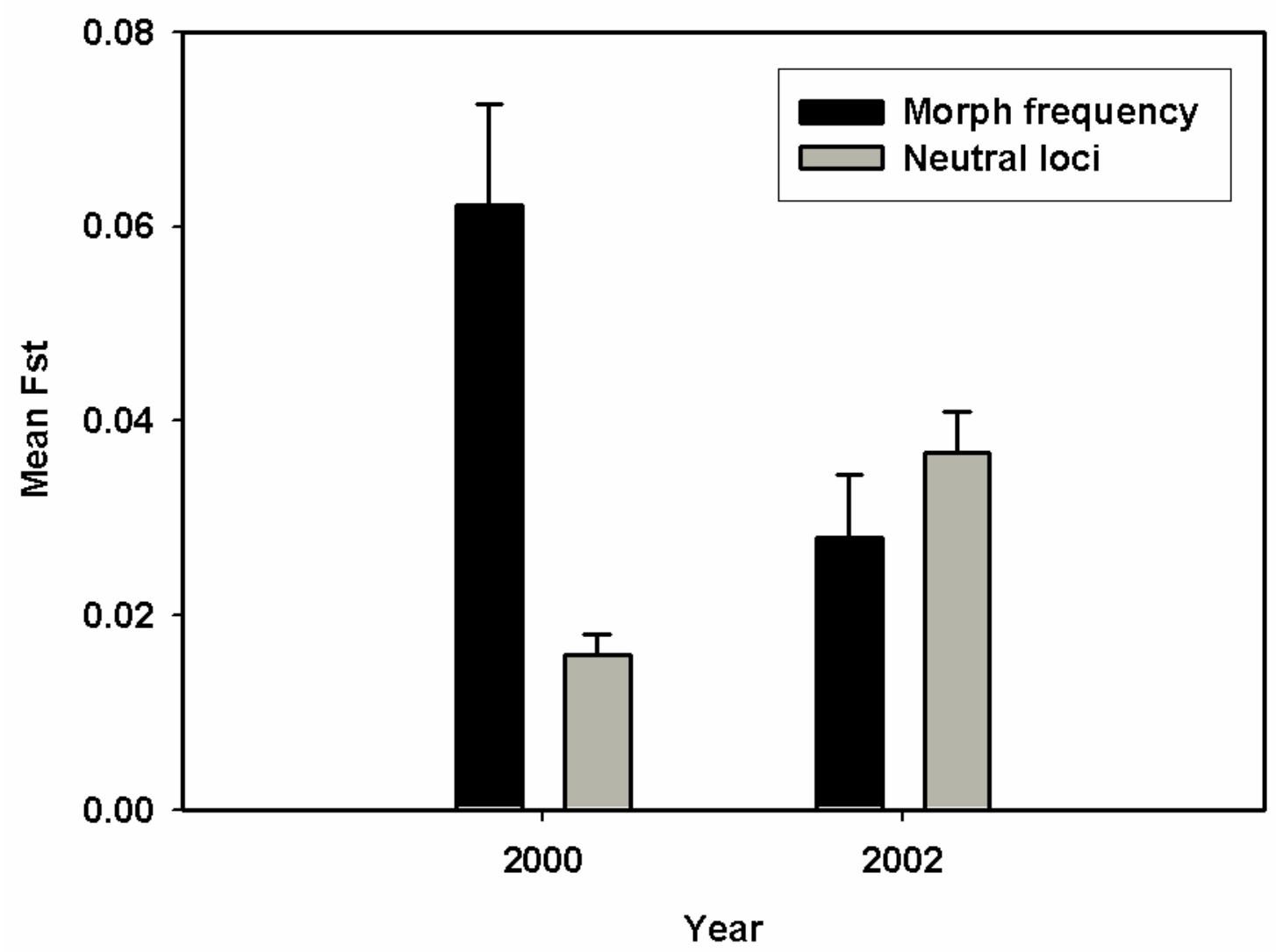

Figure 2 


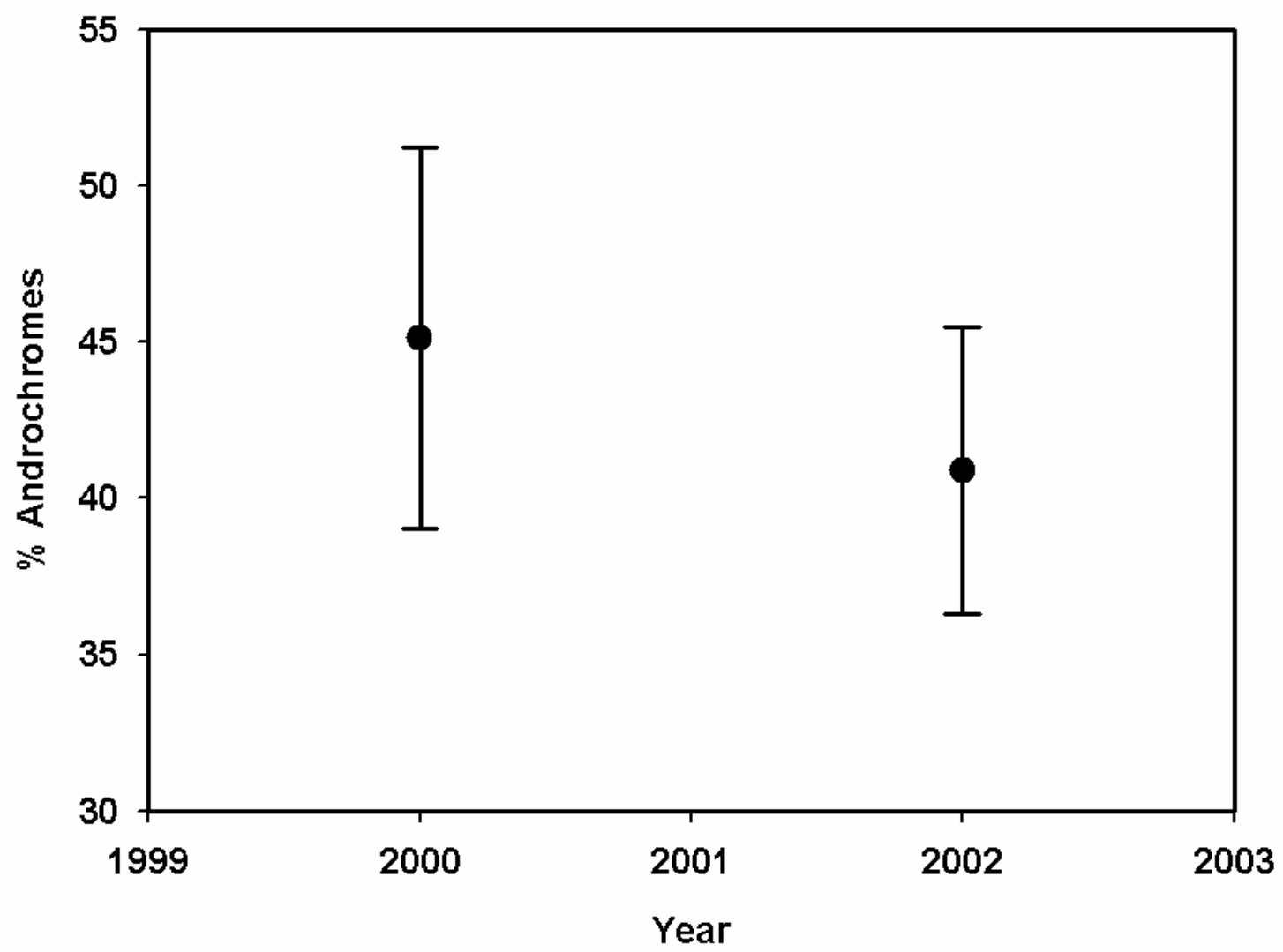

Figure 3 